\title{
Through the eyes of children: Exploring Grade 7 career aspirations
}

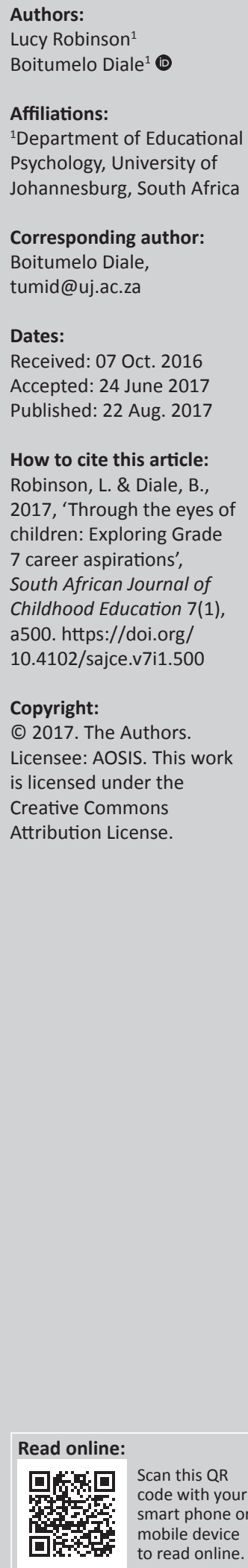

Background: The shift in recent years towards the lifespan concept of career development, which views career behaviour as occurring in stages beginning in childhood and continuing throughout life, has meant that it has become increasingly important to assist learners in fulfilling their career goals. There is, however, a scarcity of research on the career aspirations of primary school learners, especially those from low socio-economic backgrounds.

Aim: This article describes research conducted on the career aspirations of Grade 7 learners at a community school.

Setting: The study is set within an interpretivist paradigm and utilises a generic qualitative research design.

Methods: The study involved a purposefully selected group of Grade 7 learners from a local community school. As part of the study, each learner completed a collage and sociogram, and took part in a group interview.

Results: Themes that emerged from the data analysis were: career aspirations that seek to fulfil hopes and dreams, the role of the family in shaping career aspirations and counting the 'cost' of career aspirations.

Conclusion: The results of the study indicated that there is a need to explore learners' career aspirations from an early age in order to expose them to various career choices in the constantly changing world of work.

\section{Introduction}

The South African context is one of the most complex and economically unequal in the world, with a quarter of the population unemployed and $20 \%-30 \%$ of the population living in extreme poverty (Statistics South Africa 2015). Furthermore, as a new democracy, South Africa has a unique sociopolitical history and has inherited a legacy of discrimination and inequality, particularly in the fields of education and career development. This legacy has led to more than half of the South African population receiving education from a historically disadvantaged school system and finding themselves still disadvantaged more than 20 years after democracy (Fleisch 2008; Taylor \& Yu 2009; Van der Berg 2008).

With the development of democracy in South Africa, education has been mandated through government acts and policies, for example the South African Schools Act No. 84 (SASA 1996) and the White Paper 6 (2001), key vehicles for the implementation of social justice. Social justice can be understood as encompassing 'actions that contribute towards affording equal access to all within a particular nation or society' (O'Brien 2001, cited in Watson 2010:24). As part of addressing the injustices in the South African school system, community schools were developed to provide alternative, quality education to children from previously disadvantaged communities and have become beacons of hope in assisting young people to overcome the complex and multifaceted transformational challenges of their history and context (Diale 2014; Taylor \& Yu 2009).

The particular community school referred to in this research was founded as a result of the number of children who could not be accommodated at the only primary school in a nearby informal settlement in the north of Johannesburg, Gauteng. Like others, this community school has aimed to meet the needs of primary school children and to provide the life-enriching educational opportunities that many South African children do not have but need in order to develop into responsible, contributing and equipped members of a transformed society (Department of Education 2002). As researchers involved in supporting the school from an educational psychological perspective, we observed that children's career stories and hopes were 
not addressed in the school, home or community context. Moreover, the body of international and local research on career development in education reveals that there is a stronger focus on high school learners (Auger, Blackhurst \& Wahl 2005; Flouri \& Panourgia 2012; Schuette, Ponton \& Charlton 2012), with limited emphasis at the primary school level (Watson et al. 2010; Arulmani 2011b). In the context of unique pre- and post-democracy challenges, less than $4 \%$ of career research reports focus on the career development of children in South Africa, and most of these focus on white, middle-class high school learners (Arulmani, Van Laar \& Easton 2001; Venter, Watson \& Fouche 2006). However, the relevance of this research to learners from different socioeconomic backgrounds is unclear, thus highlighting the social injustices of the past and the need for transformation in the field of career development in order to reflect a democratic country. Given the association between low socioeconomic status and unemployment, often learners of lower socioeconomic status need the most assistance in terms of career development (Chartrand \& Rose 1996).

Career development forms an integral part of a learner's overall development, particularly during adolescence (12-20 years), during which significant biological, cognitive, social and emotional changes take place as preparation for adult life begins (Geldard \& Geldard 2012; Watson 2010). In keeping with a social justice perspective, career development is defined by Watson (2010) as:

one that exposes previously and currently disadvantaged children to the world of work, to career education, to tertiary institutions and career role models in ways that are contextually relevant and sustainable (p. 25)

An exploration of young people's hopes and expectations of pursuing a career in a certain field is a helpful starting point.

It is against this background that this article sets out to illuminate the career aspirations of a group of Grade 7 learners from a community school. The research question addressed is: 'What are the career aspirations of Grade 7 learners in a community school?' It is envisioned that the findings of this study can assist in: the implementation of contextually relevant career intervention strategies in schools and communities, providing exposure to the world of work and career education to learners in South Africa whose knowledge on this important aspect of their lives is limited and allowing learners to nurture hope for their future through gaining knowledge about careers, making important decisions regarding their future careers, overcoming potential career barriers and pursuing their aspirations with a sense of hope for the future (Auger et al. 2005; Flouri \& Panourgia 2012).

The article begins with a conceptualisation of adolescents' development from Western and African perspectives as expounded in theories of human development. We present Gottfredson's (1981) theory of circumscription and compromise as the theoretical framework that grounds the career development of adolescents discussed in the article.
A literature review of adolescent career aspirations and community schooling is then provided. Thereafter, a description of the research design and methodology includes the multiple methods used to explore the career aspirations of three black male adolescent participants in a community school. We then present a discussion of the salient issues pertaining to the career aspirations of adolescents from disadvantaged contexts. We conclude by suggesting specific areas for further research into contextually relevant career interventions for marginalised communities wherein the need for career development is so great.

\section{Perspectives on adolescents' development, career aspirations and community schools: Same lens, different views}

The adolescent stage occurs between the ages of 12 and 20 when significant biological, cognitive, social and emotional changes take place as preparation for adult life begins (Geldard \& Geldard 2012). Schoon and Polek (2011) state that adolescence is a critical juncture in the development of an individual's career, given that the hopes and expectations expressed by young people during adolescence can potentially have important consequences for later development. In this article, we explore adolescent development from two world views, namely a Western and an African perspective. The key theories that guide this article are Erickson's theory of psychosocial development (Donald, Lazarus \& Lolwana 2002), which is contrasted with Nsamenang's theory from an African perspective that proposes the influence of social ontogenesis on human development. However, we conclude this discussion by arguing that there is a need for these theories to intersect in relation to developing children and their career aspirations within the diverse South African sociocultural context.

Important to Erikson's theory of psychosocial development is the emphasis that it places on the social context. Meece and Daniels (2008) note that Erikson's theory acknowledges that relationships and societal expectations have an effect on an individual's development. During the adolescent stage, rapid changes occur at the social, emotional, cognitive and physical levels. The formation of an identity is key at this stage and fundamental for entry into adulthood. Furthermore, for adolescents, this stage includes figuring out what they are capable of in their own capacity as well as how this translates into what they can achieve as members of society (Hook 2009). They, therefore, begin to shape their career aspirations as they struggle with identity versus confusion and purposefully seek out career options and begin to make career choices (Hook 2009). The successful resolution of the adolescent stage results in a well-developed sense of identity that reflects individuality, continuity and stability, whereas an unsuccessful resolution can result in role confusion. Hook (2009) explains that this confusion can surface in various ways, for example in an inability to settle on a career. 
It is, therefore, our opinion that the exploration of career aspirations at the beginning of this developmental stage is essential in assisting young people to establish secure career identities.

Many Eurocentric stage-approach theories of development, like Erickson's, propose a linear progression of development. These theories are homogenous and fail to account for cultural differences that acutely affect the development of adolescents in the African context. Bronfenbrenner (2005) argues, however, that a consideration of the influence of varying and unpredictable contextual factors on human development is essential. The cumulative influences of an individual's varying contexts can in fact mean that development is a non-linear process (Nsamenang 2009).

We therefore contrast Erikson's theory with that of Nsamenang (1992), who asserts that cultures exert different influences on human development insofar as they may recognise, define and assign different developmental tasks to the developmental agenda, thereby making development different across cultural groups (Nsamenang 1992). Nsamenang (1992), therefore, proposes a theory of social ontogenesis in which human development is inextricably linked to the ecology and social system in which development occurs. Ontogenesis in isolation relates to the developmental unfolding or lifetime development of an individual; however, social ontogenesis relates to the individual's development within a social system and it is social ontogenesis that anchors human development (Nsamenang 2005). According to Nsamenang (2005:3), 'there are distinctive developmental tasks that are defined within the framework of cultural realities and developmental agendas'. This focus on the role of the cultural context in development thus differentiates Nsamenang's theory from individualistic accounts of human development such as Erikson's. For Nsamenang (2005), as children actively engage in cultural life, they gradually assume levels of personhood, identity and ways of being. Furthermore, within an African worldview, an individual can only achieve a sense of self through a community (Nsamenang 2005). Bronfenbrenner's (2005) bio-ecosystemic framework further alludes to the dynamic interplay and influence of various systems in an individual's life, with the community and larger society playing vital roles in the development of the young person. It is at the adolescent stage of development that many African cultures would practise initiation ceremonies characterised by accentuated efforts to allocate more responsibility to adolescents and to begin to incorporate them into adult social groups and roles in preparation for adulthood (Nsamenang 1992). Given that the participants in the study on which this article is based were African adolescent boys and therefore at this transitional stage of their development, it is important to note that as adolescents enter into the emerging adult stage and are incorporated into adult social roles, their career aspirations are likely to be shaped. As they form a secure identity and sense of self after the successful resolution of Erikson's Stage 5 and are successfully initiated into adult life (Nsamenang 1992), it is likely that they will be exposed to careers from an adult perspective and possibly take on certain work tasks; they will, therefore, begin to evaluate careers as socially acceptable or unacceptable (Gottfredson 1996).

Gottfredson's (1981) theory of circumscription and compromise proposes that adolescents evaluate themselves against others in the process of establishing a sense of self. Adolescents become sensitive to social evaluation and aware of which careers are deemed acceptable and unacceptable within their context. The relation between early adolescents' need to 'fit in' with their peer group and their need for affirmation from others regarding their future career choices is highly likely to impact their career aspirations. When exploring the career aspirations of learners at this stage of development it is, therefore, important to be cognisant of the fact that peer agreement and validation play key roles in defining an individual's aspirations. It is our contention that there is a discernible link between Erikson's psychosocial development theory and Gottfredson's career development theory. With a secure identity, an adolescent would be expected to have enough of an understanding of self to explore careers congruent with who they are, and not who their peers or wider social circle may perceive them to be. Furthermore, the concept of social ontogenesis relates to both Gottfredson's and Nsamenang's theories in that they take into account the environmental and social issues affecting adolescents' career development, helping them to gain a better understanding of themselves and their potential careers so that their 'social space' or 'zone of acceptable alternatives' becomes narrower (Gottfredson 1996:187). At this stage, adolescents are also able to incorporate new elements into their self-concept.

Although many Western theories of career development have been criticised for being irrelevant within a South African context - particularly because they do not account for multicultural, sociopolitical and economic factors that pervade South African life (Watson, McMahon \& Longe 2011) we suggest that a combination of the abovementioned theories can be relevant to a South African context in that they give sufficient focus to broader environmental and societal issues, as well as to socioeconomic status (Watson et al. 2011), and thus provide a 'melting pot' (Figure 1) of perspectives and a much-needed theoretical intersection for exploring the career aspirations of adolescents in South Africa.

\section{The melting pot of Eurocentric and Afrocentric perspectives on adolescents and their career development}

Career aspirations can be understood as the individual's hopes and expectations of pursuing a career in a certain field. Many such aspirations are based on societal norms and parental expectations, and are also influenced by various contextual factors (Flouri \& Panourgia 2012; 


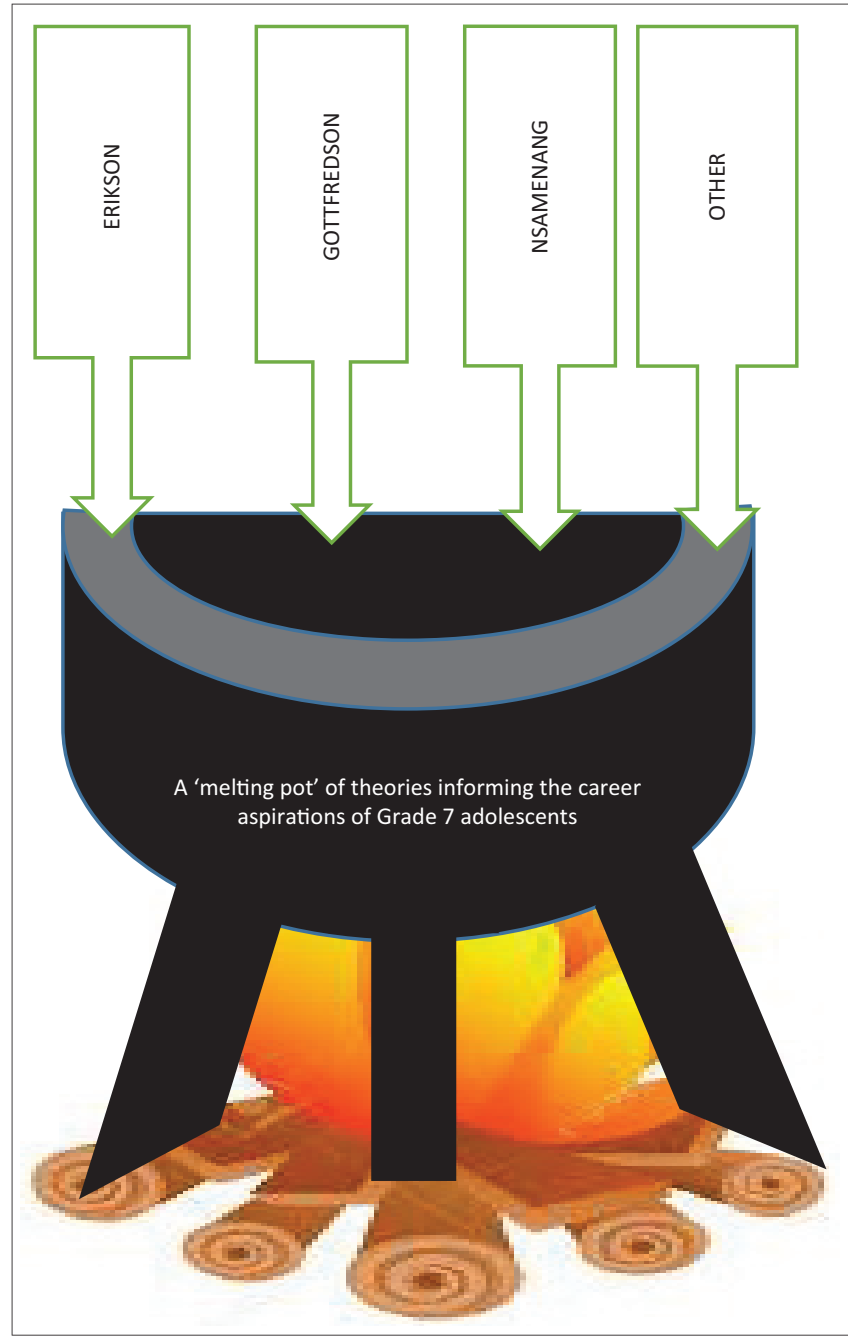

FIGURE 1: The melting pot of Eurocentric and Afrocentric perspectives on adolescents and their career development.

Nagengast \& Marsh 2012). Although having career aspirations does not guarantee work in a certain field, a sense of hope and expectation for the future motivates a person to meet their long-term educational and career goals (Quaglia \& Cobb 1996; Schuette et al. 2012). Career aspirations can be likened to a life compass, giving a person direction in terms of their investment of time and energy (Ashby \& Schoon 2012). The importance of exploring career aspirations lies in the fact that maintenance and nurturance of these aspirations can lead to a greater sense of well-being and a more positive sense of self (Ashby \& Schoon 2012). Although we acknowledge that career aspirations are influenced and sometimes thwarted by elements such as limited financial resources, family, societal and cultural expectations, as well as the quality of education received, we believe that if we are to attempt to assist young people in realising their career goals, an understanding of their future hopes and expectations is crucial.

According to Patton and Skorikov (2007), literature regarding the career development of children and adolescents, and more specifically their career aspirations and expectations (Patton \& Creed 2007), is limited. This is problematic, given the importance of career aspirations proposed in most theories of career development, including Gottfredson (1981) and Zunker (1994). Patton and Creed (2007) observe that there is a move towards placing greater emphasis on the role of context in the development of adolescents' career aspirations. Furthermore, Schoon and Polek (2011) contend that research is needed that assesses the link between career aspirations and the attainment of those aspirations. Studies of this kind are thus finally beginning to emerge (Rojewski 2005, cited in Patton \& Creed 2007).

Schoon and Parsons (2002) maintain that emphasis has traditionally been placed on individual factors in studies of the development of occupational aspirations, and they argue that this emphasis tends to elide the constraints of the social circumstances within which adolescents aspire. Furthermore, there is an awareness internationally that, for many adolescents, 'vocational development depends more on existing opportunity structures than choice' (Schoon \& Parsons 2002:262). Research by Furlong and Cartmel (1995, cited in Patton \& Creed 2007) indicates that the occupational aspirations of adolescents as young as 13 years are constrained by their perceptions of local work opportunities.

Empirical studies on the career aspirations of primary school children have been conducted in Australia, China and the United Kingdom. These studies have focused on career aspirations as indicators of future careers, as well as on the influence of aspects such as gender, self-efficacy and socioeconomic status on adolescents' career aspirations (Creed, Wong \& Hood 2009; Patton \& Creed 2007; Schoon 2001). This research shows that stereotyping plays a role in adolescents' career aspirations. A study of 498 Chinese high school students (Creed et al. 2009) found that, although both boys and girls aspired to enterprising careers, boys typically aspired to investigative careers, whereas girls aspired to conventional careers. Research by Rojewski and Yang (1997, cited in Patton \& Creed 2007) found that self-esteem had a minimal effect on American adolescents' career aspirations, but Lapan et al. (2000) found that Grade 7 learners expressed a higher sense of self-efficacy when they believed that their aspirations matched the conventions associated with their gender.

According to Patton and Creed (2007), socioeconomic status has long been identified as an influence on career aspirations, yet it has been infrequently researched. The research that has however been conducted indicates that higher socioeconomic status has a positive effect on the ultimate fulfilment of career aspirations, whereas lower socioeconomic status, together with a perceived lack of parental support, negatively affects the attainment of career aspirations (McWhirter, Hackett \& Bandalos 1998, cited in Patton \& Creed 2007). A 17-year longitudinal study conducted by Schoon (2001) in the United Kingdom, with a national representation of 7649 individuals born in the United Kingdom, indicated that career aspirations are indeed a reliable indicator of future careers. Continued study in this area is necessary for many reasons, one of which is to provide support and intervention in helping adolescents to achieve their career goals. 
South Africa has a unique sociopolitical history and has inherited an unfortunate legacy of inequality in terms of employment, socioeconomic status and education, creating a complex and challenging context for career development (Watson et al. 2011). For example, in recent decades, over one-third of a million school-age children have remained out of school and, of the children in school, the success rate of progression through grades is low (Govender 2009, cited in Watson et al. 2011). When exploring the career aspirations of primary school children it is essential to consider the context in which an individual is embedded, given that 'South Africans are faced with unpredictable contextual factors that often negate the conceptualisation of linear individual career development' (Watson \& Stead 2002:28). These contextual factors include, but are not limited to, socioeconomic status, poverty and education, and these factors form potential barriers to the achievement of an individual's career aspirations. More specifically, career barriers can be defined as 'events or conditions, within the person or in his or her environment, which make career progress difficult' (Swanson \& Woitke 1997:434). Lent, Brown and Hackett (2000) observe that:

people are less likely to translate their career interests into goals, and their goals into actions, when they perceive their efforts to be impeded by insurmountable barriers or inadequate support systems. (p. 38)

Current research on the career aspirations of primary school children remains problematic because the socioeconomic status of samples used are not specified (Watson et al. 2011). The participants in this particular study all come from low socioeconomic backgrounds and reside in local informal settlements. The influence of this context on their career aspirations is, therefore, important because, as Arulmani (2007) asserts, there is a trend for children from low socioeconomic backgrounds, whose parents are illiterate and unemployed, to exhibit a high tendency to prematurely discontinue their education and to enter the world of work as unskilled labourers.

According to Hartung, Speight and Lewis (1996), there is a dominant perception in society that career choice is an individual process of self-discovery based on interests, values and aspirations. Although there is an undeniably individual element to career choice, it is also a communal, interpersonal process (Hartung et al. 1996) and therefore, when exploring the career aspirations of primary school children, the interdependence of various aspects of a person's context, such as schooling and family, in shaping their aspirations cannot be ignored.

In South Africa, family has been identified as a key social influence on the career aspirations of young people (Watson et al. 2011). According to Watson et al. (2011), there is general consensus in literature that children's occupational aspirations are consistent with the occupations of their parents. However, this is mediated by their perception of their parents' occupational satisfaction. This family dynamic has a strong impact on children of unemployed parents as they do not have any influential role players in their immediate family system.

Stead (1996) contends that culture is an important aspect of career development as its values and constraints shape an individual's career aspirations. Given its multidimensionality and fluidity, as well as the limitations of individual perspectives, culture is a difficult concept to define. However, it is generally described as the attitudes, behaviours, traditions and knowledge by which a certain group of people abide, and these characteristics are passed on from one generation to the next (Dalton, Elias \& Wandersman 2007, cited in Visser \& Moleko 2012). Stead (1996) explains that the apartheid regime in South Africa sought to polarise culture and accentuate its differences rather than similarities. Although there is much debate regarding what constitutes the term 'African culture', black-African culture has been seen to embody a communal perspective of dependence and cooperation and can be likened to an intricately woven tapestry (Nsamenang 1992). With cultural 'dualism' in mind, it is necessary to consider how a collectivist cultural background as opposed to an individualist one may influence the career aspirations of primary school children (Bojabotseha 2011; Diale 2014). This is especially significant given that the participants in this research come from Tshivenda, isiZulu and isiXhosa backgrounds. Hartung et al. (1996) assert that cultural variables such as individualism and collectivism mediate vocational behaviour and cause individuals to bring differing expectations, aspirations and values to the career development process. We assert that, whilst culture plays an important role in the career aspirations of adolescents, it should not be emphasised over other relevant aspects, for example, the influence of the school community.

School has been identified as another social influence on an individual's career development (Watson et al. 2011). Generally speaking, schools can be viewed as social institutions that provide a platform for career development to take place (Shumba \& Naong 2012); they are in a position to influence the career aspirations of learners through the curriculum, career guidance programmes and the provision of career role models (such as teachers). Career role models may play an important role in assisting young people to regulate their career aspirations, especially given that research indicates a trend towards high levels of unrealistic occupational aspirations, particularly amongst more disadvantaged learners (Watson 2010). This research's focus is on a fairly new form of school, namely the community school. A community school is an independent school subsidised by government funding as well as community and individual donations. Such schools aim to offer quality education provided by qualified teachers who take a personal interest in each learner. The community school where the research of this study was conducted provides education to underprivileged learners who live in surrounding informal settlements.

It is important to note that, at a Senior Phase level, the Grade 7 Life Orientation curriculum contains a learning outcome called 'The World of Work' wherein learners are taught about 
different careers through lesson activities relating to career fields as well as educated in the value of choosing a career that fulfils an individual's personal needs and potential. This learning outcome also includes information on qualities relating to each career field: work environment, activities, opportunities and challenges (Department of Education 2011). In this sense, the curriculum teaches adolescents to evaluate different careers; they, therefore, begin to 'weigh up' acceptable and unacceptable careers, as Gottfredson (1996) has noted.

According to Arulmani (2011b), there is a growing need for approaches to career guidance that serve individuals from differing backgrounds and that resonate with these various backgrounds. This transformation in approaches to career guidance would include gaining knowledge about the ways of life and the worldview of the community of the individual to whom the career guidance is given (Arulmani 2011b). Watson (2010) concurs with Arulmani (2011b) by stating that one of the ways in which South Africa can move towards a social justice perspective within career psychology in developing countries would be to redefine the discipline through instituting inclusivity and better access to career guidance programmes (Watson 2010). An investigation of the career aspirations of young people should usually begin to lay the foundation for these types of career guidance programmes to be implemented in primary schools.

\section{Methodology Research paradigm}

Within the interpretivist paradigm, a qualitative research approach was chosen for this research that acknowledges the subjective meaning (De Vos \& Strydom 2011) that primary school children attribute to their career aspirations. The research aims to capture aspects of the participants' lives in order to understand and interpret meaning (Henning, Van Rensburg \& Smit 2004).

\section{Research design}

This research aimed to explore the career aspirations of Grade 7 learners from a particular community school. A generic qualitative design was, therefore, chosen. Central to a generic qualitative research design, and using multiple data collection methods, is the premise that individuals construct reality in interaction with their social worlds. Consequently, a generic qualitative design includes elements of description, interpretation and understanding (Merriam 2009).

\section{Data collection}

Participants of this study included three Grade 7 male learners, aged between 12 and 13 years, from an informal settlement and attending a local community school in the north of Johannesburg, Gauteng. They were part of 26 learners in a Grade 7 class and were selected to participate in the research as they had already undergone scholastic assessment conducted by the first researcher in 2013 when they were in Grade 6. During this period, a rapport between the participants and the first researcher was established. Biographical information had been obtained for the participants from interviews conducted with their parents in 2013 as part of the assessment process. Purposive sampling was used. For the purposes of anonymity, we refer to them as Participant A, Participant B and Participant C. A brief background of each participant is provided in Figure 2.

As an integral part of the interpretivist approach to this research, data were collected through collages, career sociograms and a semi-structured group interview. Besides triangulating data, the decision to use different media visual imageries (collages and sociograms) as well as verbal descriptions (group interviews) of participants' career aspirations - was twofold. Firstly, as researchers in the field of educational psychology, we believed that visual media would allow the participants to express their sociocultural backgrounds. In addition, they would be able to express their

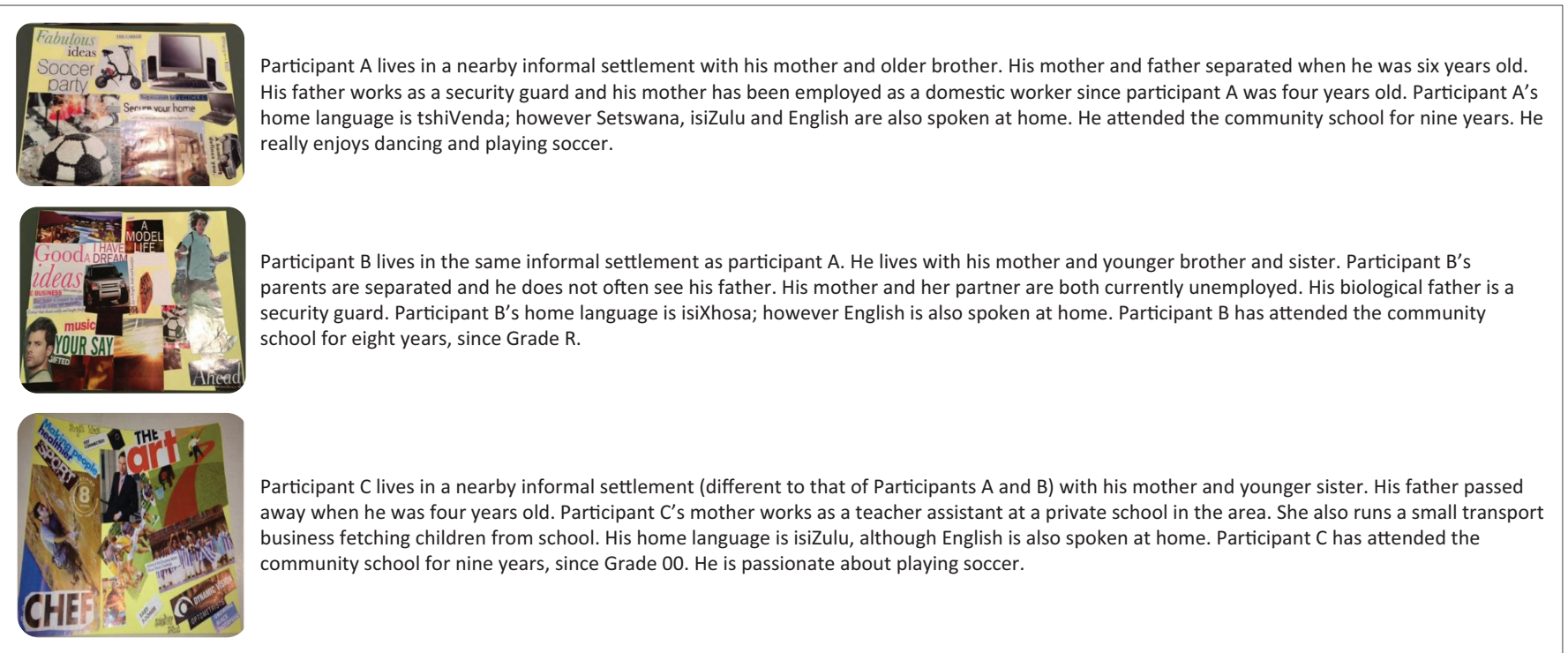

FIGURE 2: Participants' background information. 


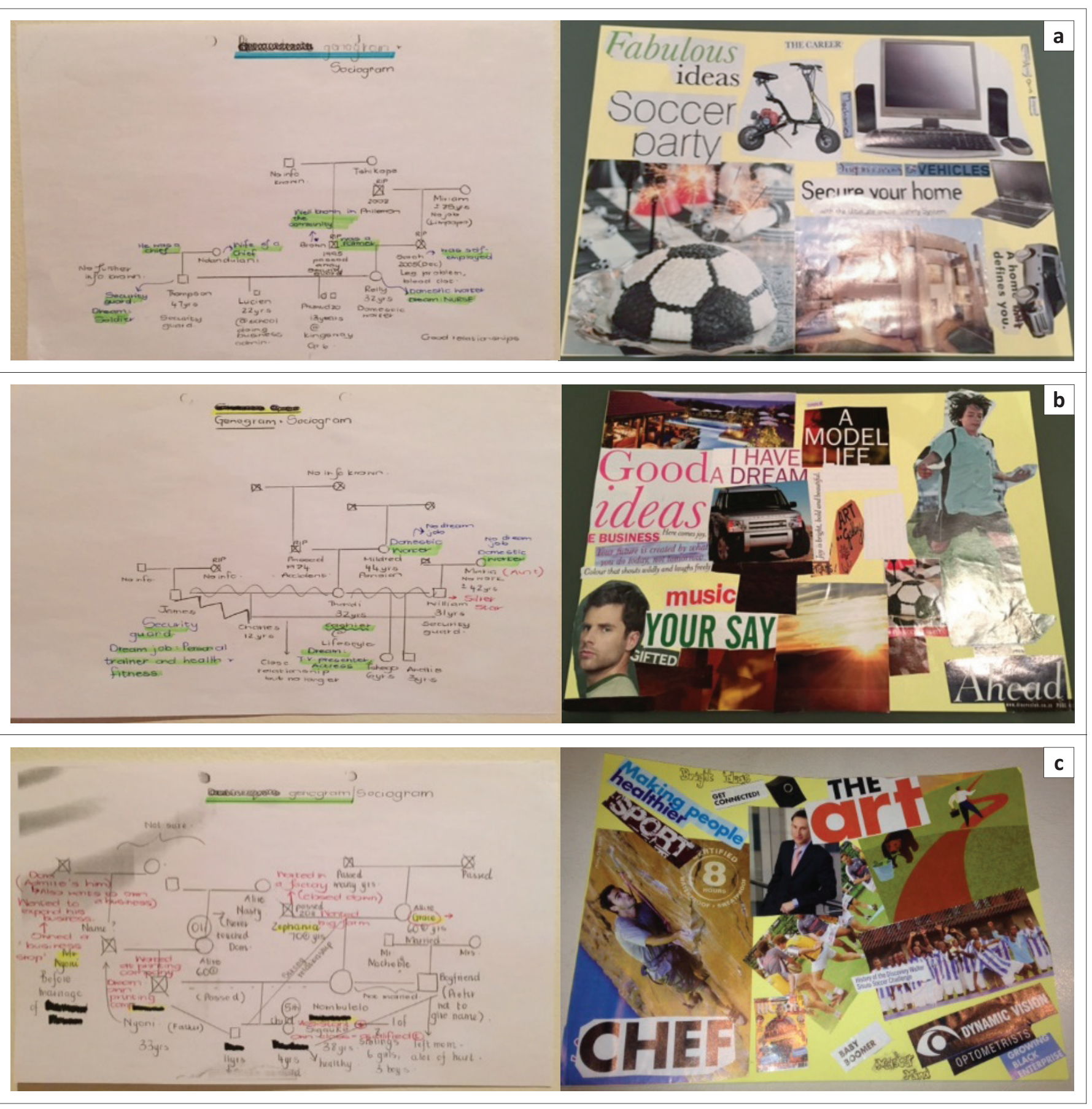

FIGURE 3: Participants' sociograms and collages. (a) Participant A's sociogram and collage. (b) Participant B's sociogram and collage. (c) Participant C's sociogram and collage.

future career hopes and dreams in a creative art activity that was informal and non-threatening. The collages and sociograms (Figure 3) formed the basis for the semi-structured group interview, which aimed to obtain specific information by exploring participants' thoughts and interpretations of their career aspirations. The group interview proved to be particularly valuable because participants were able to hear one another's career hopes, which enabled a rich conversation.

\section{Data analysis}

Participants' written descriptions as well as data from group interviews in which they described their sociograms and collages were analysed using content analysis. An inductive ('bottom-up') process of data analysis was employed along with Creswell's (2012:237) steps for data analysis, which included the collection of data based on the research question, the preparation and organisation of data for analysis, reading through all the data, colour coding the data, using the codes to generate themes, identifying interrelated and interconnected themes and, finally, interpreting the meaning of the identified themes. The analysis of both the sociograms and collages and the written descriptions revealed similar themes relating to participants' career aspirations and their experiences as learners coming from contextually disadvantaged 
backgrounds in which career role models are lacking in their day-to-day lives.

\section{Trustworthiness and ethical considerations}

At the start of this research, ethical clearance was granted by the University of Johannesburg (South Africa), Clearance Number: 2014-064. Following this, ethical standards were adhered to based on the work of Babbie and Mouton (2001). These included voluntary participation, no harm to participants, anonymity and confidentiality, not deceiving subjects, and accuracy of analysis and reporting.

\section{Discussion of findings}

The research explored the career aspirations of Grade 7 learners in a community school and its findings yielded three main themes and seven sub-themes. The findings indicate that the participants have definite career hopes and dreams as indicated in Figure 4.

\section{Career aspirations that seek to fulfil hopes and dreams}

In unpacking career aspirations relating to participants' hopes and dreams, three sub-themes emerged: participants valued future careers that would allow them independence and autonomy; they hoped for careers that would afford them better lifestyles and, finally, they aspired towards lasting careers that are sustainable.

\section{Aspiration towards a career that allows independence and autonomy}

When discussing the career hopes and dreams of the participants it is necessary to bear their stage of development in mind as this has a profound influence on their career aspirations. As adolescents, all three participants aspire towards a career that will give them independence and autonomy. Independence can be understood as freedom from the control of others and the autonomy to think, feel and make decisions on one's own (Russel \& Bakken 2002). Career aspirations are understood as a person's hopes and expectations of pursuing a career in a certain field (Flouri \&

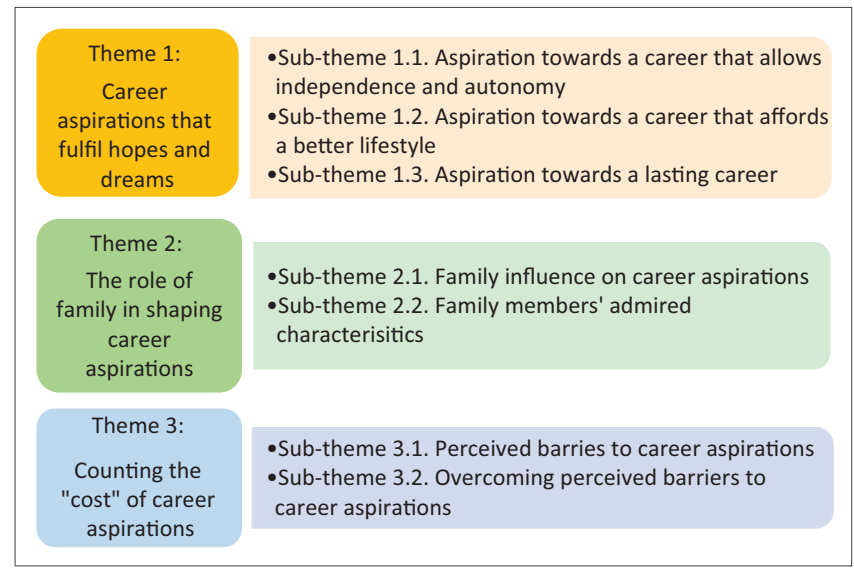

FIGURE 4: Main and sub-themes that emerged from the analysis of the different forms of data.
Panourgia 2012; Nagengast \& Marsh 2012) as well as the outcome of pursuing a certain career. A phrase from Participant A's collage, 'managing your own company', with the word 'own' handwritten by the participant, indicates that he does not want to manage a company but to own his own company. Participant B's phrase 'I have a dream' on his collage suggests that he has a dream for his future and that he is taking ownership of his future career. Participant C's phrase, 'growing black enterprise', and handwritten words 'bright ideas' and 'master mind', relate the idea of empowerment and growth to autonomy for black-owned businesses. They also reveal the bright ideas he has for his future, indicating his desire for independent thought. All of the collages contain elements that reveal the aspiration towards a career that allows for independence and autonomy. Of the collage, Participant A said the following in the group interview: 'Just like managing your own company of computers and stuff'.

'I want to do business. I want to own a business'. ... 'Teacher, it's like managing your own company and owning your own company and not working for someone else ... and working for your own self and have employees, ja ... it's my biggest dream.' (Participant A)

All of this directly relates to the notion of a career that allows for independence and autonomy.

According to Gottfredson's (1996) stages of career circumscription and compromise, the participants are currently aware of an occupational hierarchy and are in the process of evaluating which careers are socially acceptable and which are not. Furthermore, in relation to Erikson's psychosocial stages of development, they are in the process of forming a secure identity and are purposefully exploring career options (Hook 2009). Ultimately, the formation of a secure identity will assist the participants to settle on a future career.

\section{Aspiration towards a career that affords a better lifestyle}

The participants' desire for careers that would offer them a better lifestyle was evident in a variety of data sources. In his collage, Participant A posted pictures of two computers, a Land Rover and a fancy house, revealing his yearning for a luxurious, upper-class lifestyle. Under the picture of the Land Rover and next to the picture of the house, the participant pasted the phrase, 'A home that defines you', which could mean that the home and other material possessions that he hopes to acquire would be things that would define who he is and perhaps give him status. There is a sense here of his belief that external resources define who he is as a person, indicating the idea of self-worth as linked to one's career. This participant currently lives in an informal settlement and does not have much by way of material possessions. Participant B, when explaining a picture of a fancy lodge on his collage, said, 'This here is a house that like it's an idea of what I want to do, I want to design my own house', whilst Participant $C$ added in the interview, 'I see myself inventing the latest technology and having a nice big house and the latest, fancy car'. 
The picture in the top left-hand corner of Participant B's collage shows a resort with a pool and a particularly glamorous outside area. This picture may depict the lifestyle that he hopes his career will one day afford him. Next to the picture he has stuck the phrase, 'A model life', which, considering this sub-theme may be a lifestyle that affords him both external value (material possessions depicted also by the pictures of the Land Rover and fancy house) and internal means (financial peace of mind including the ability to provide for his family). Participant B's phrase, 'your future is created by what you do today, not tomorrow', may indicate that he is willing to work hard to create a future that will mean a better life for him. This quote links to Bandura et al.'s (2001) research on self-efficacy in that it suggests that the participant has a belief in himself and his ability to produce a desired outcome if he is proactive. Bandura et al. (2001) maintain that self-efficacy is defined by an individual's belief in their ability to succeed in a specific situation and to produce a desired outcome, which this participant displays by including this phrase in his collage.

In explaining what would be a better lifestyle, Participant $C$ stated, 'I want a BMW and a Land Rover'; Participant A added, 'It's like a home that satisfies you if at where you live is fine for your life'. This sub-theme of aspiring towards a better lifestyle links to Flouri and Panourgia's (2012) suggestion that primary school children's career aspirations may reflect their hope for the future rather than suggest realistic possible careers. In other words, the participants' hope for their future includes the accumulation of material possessions that symbolise a better life rather than the reality of a specific career choice. The participants' desire for fancy material possessions (afforded to them through their future career) was influenced by their family backgrounds. It was evident from the contrast between participants' career aspirations and their families' current jobs that the participants aspire to careers that will afford them a much better lifestyle than they currently experience.

\section{Aspiration towards a lasting career}

Even though they are in primary school, the participants are 'weighing up the odds' of certain careers and 'are not willing to take' (Participant A) certain careers because of the concern that they will end prematurely. Although all three participants included pictures in their collages of soccer teams and players, when asked if they would pursue soccer or sport as a career one day their responses indicated reluctance because of the belief that such a career would not last. This reluctance is effectively encapsulated in Participant C's response (with which the other participants agreed) to the question of why he would not choose to be a soccer player one day. He answered:

'That's because like having winning careers, when you are done with soccer, in soccer your career can end. After your career ends, you must like maybe think of ideas that if your career ends now you at least have some ideas like business and stuff, ja, so I don't choose soccer. I'm not willing to take it ... in case it ends.' (Participant C)
Later in the group interview, Participant B echoed Participant A and C's comments when he said, pointing again to the picture of the boy kicking a soccer ball, a picture indicating a sports career, 'It's just this one is too short'.

Although the participants in this study were relatively young (12 and 13 years of age), it was evident that they were already involved in a process of evaluating the security and longevity of their future careers as entrances to a better lifestyle. This was aptly summarised in the group interview when Participant B responded:

'Teacher I have learned that in life, with any career you must first value [evaluate] it and see how long it is going to last ... and then make a decision about whether you are taking it or leaving it.' (Participant B)

These findings also correlate with Savickas (2003) and Maree's (2011) views that a career is an individual construction intimately linked to a person's life story. It would appear that the research participants are not constructing their career narratives based on those of their parents or family members. Rather, they see their current circumstances as something to overcome, which a successful career could enable.

\section{The role of family in shaping career aspirations}

The findings of this research confirm that families do indeed influence an individual's career aspirations. This outcome corresponds with literature by Hartung et al. (1996) and Watson et al. (2011), who state that career choice is not only an individual process, but that it is also communal and interpersonal. The data yielded two sub-themes, namely: family influence on career aspirations and family members' admired characteristics.

\section{Family influence on career aspirations}

Although none of the participants aspired to any of their family members' occupations, their family members had encouraged them in one way or another to achieve their dreams and cautioned them not to make the same mistakes that they had made. Participant B pertinently captured his family's influence upon him when he stated:

'What stood out for me is like they [his parents] told me like I should work hard and get degrees so that I can achieve my dream and don't be the same like them.' (Participant B)

Participant A responded with, 'They said I must not make the same mistakes as they did'. He continued by saying:

'Both of them, they were actually achieving but something stood in their way and I don't know what. Yes, then they said it was a mistake. They said they cannot stop me from living my life, but they want me to know what is right and what is wrong, and mistakes, like when you make a mistake, and I can ruin my life by that mistake.' (Participant A)

When Participant $C$ was asked if there are any family members' careers that he would like to follow, his response was 'I have no one'. There is congruency in this conversation with Matsebatlela's (1986, cited in Stead 1996) statement that 
there is a general expectation of children of parents who are unskilled labourers or who are unemployed that they will enter into careers that will provide a steady income and bestow professional status.

Similar responses were noted in the participants' sociograms, which indicated that the participants' parents' current careers played a role in shaping participants' desires to be different and have independence and autonomy in their future careers. An analysis of the sociogram indicated that Participant A partly aspires to his father's dream career of becoming a soldier; however he does not want to become a security guard. Participant B stated that he also aspires in some way to his mother's dream job of becoming a presenter. Participant B mentioned that his oldest aunt is a domestic worker and he does not aspire to that because it cannot support him. Participant $\mathrm{C}$ mentioned that he does not aspire to a career in teaching, which was his mother's dream job. Participant $C^{\prime}$ s father's dream job was to own a printing company and Participant $C$, along with the other two participants, also aspires to own a company one day. For Participant C, the memory of his father, who is deceased, and his father's dream of owning a company, is likely to have influenced his own aspiration.

Although Gottfredson's (1996) theory of circumscription and compromise asserts that children from low socioeconomic backgrounds do not aspire to hold more prestigious careers than their parents or significant caregivers because they fear failure and separation from their families, the findings of this research contradict this assertion. The participants in this research appear to aspire towards careers that hold more prestige than those of their parents or close family members. From an African perspective, Nsamenang (1992) states that the development of the self is inextricably linked to community, culture and the fulfilment of certain key roles. Family, therefore, plays a significant role in the career aspirations of the participants in this study.

\section{Family members' admired characteristics}

Although none of the participants aspire to any of their family members' current careers, it was clear, particularly during the group interview, that they admire certain family members' personal characteristics. These 'character qualities' appear to have inspired the participants to reach their career aspirations, despite obstacles that may stand in their way. Although Participant A was not particularly forthcoming in the group interview with regard to this sub-theme, Participants B and C made some interesting comments that highlighted the specific characteristics of family members that they admire. In explaining what he admires about his aunt, for example, Participant B said:

'Like she is the second born of my grandmother and she chose to go on no matter what. Yes and all of them in my family they didn't have a chance to go to school, but some did, so my aunt did not but she made something and um now she has bought a car and she is in Cosmo and she works here at Lifestyle.' (Participant B)
It is evident that whilst Participant B does not want his aunt's career, he admires her determination and perseverance through difficult circumstances to get to where she is today. Participant $C$ stated that he admires certain characteristics in his mother and said, 'Because she worked hard, Teacher, because she worked hard to be where she is today'. This participant has confirmed that what he admires about his mother's career is not the actual job that she does but rather her perseverance and effort. This relates to the notion of personhood as described by Nsamenang (1992) in his theory of human development: as adolescents are immersed in the world of the emerging adult, so they learn certain ways of being through observing the behaviour of those within their community. They observe qualities such as determination, responsibility and perseverance despite hardship, which they attempt to emulate and which form part of their future career aspirations.

All three participants identified one or more family members that they particularly admired for showing qualities such as determination, a good work ethic and gratitude. The participants showed awareness of their admiration in statements such as:

'I am growing up in a family that wants his or her child to achieve their goals and persevere and not do the mistakes they've done' (Participant B), and, 'My background has influenced me to look where I came from and focus on the future' (Participant C).

Although research by McWhirter, Hackett and Bandalos (1998, cited in Patton \& Creed 2007) found that lower socioeconomic status correlated with a perceived lack of parental support that negatively affected the attainment of career aspirations, it would appear that participants in this research, all from lower socioeconomic backgrounds, perceive support and encouragement from their parents in attaining their future career dreams.

\section{Counting the 'cost' of career aspirations}

It became evident in the analysis of the data that the participants are aware of potential barriers to achieving their career aspirations. They therefore experience 'anticipatory compromise' (Gottfredson 1981). Findings thus show that the participants have a fairly nuanced understanding of what it is going to take for them to achieve their career aspirations. Furthermore, they possess a determination to work towards their future career goals in spite of the barriers they might encounter, and this illustrates that they have what Arulmani terms 'persistence beliefs' (2011a:25). The research elicited two sub-themes: perceived barriers to career aspirations and overcoming perceived barriers to career aspirations.

\section{Perceived barriers to career aspirations}

The participants perceive that the main barrier to achieving their career dreams is money, an understandable perception given their impoverished living circumstances. In his collage, Participant $C$ included a picture of a man walking along a path with a briefcase in his hand; to the left of the path is a 
bear with a bucket of money in front of it from which it is eating. In thinking about barriers to career aspirations, this picture could indicate that the bear symbolises barriers (or simply an overt threat) to the participant's career aspirations. The 'bear' or barrier could take the form of money, resources or poverty, for instance. When asked if he could think of any 'bears' that might try and 'eat up' his career dream, Participant $C$ responded with:

'Ja, it's like someone who like who doesn't want you to succeed and blocking all your ways and starting your business you need to have money and buy equipment that's another trouble thing.' (Participant C)

Participant B responded to the notion of money as a barrier by saying:

'Um ... money. ... Like when I go to university, like some people, like they can't afford, couldn't afford to go to university. So if it's too much for my family, so I won't have to go, so I will make a plan.' (Participant B)

Literature by McGrath and Akoojee (2007), Arulmani (2011b) and Watson et al. (2011) indicates that poverty and socioeconomic status are obstacles to the development of children's career aspirations and the continuity of their education. Participants are aware of this barrier and its likelihood to affect the attainment of their career dreams.

\section{Overcoming perceived barriers to career aspirations}

Key elements in the data sets spoke pertinently to the subtheme of overcoming perceived barriers to career aspirations. In his collage, Participant B included three phrases which speak of being proactive and overcoming obstacles, such as, 'your future is created by what you do today, not tomorrow'. 'I have a dream' relates to having a vision for the future that will help when times are tough and when there are obstacles in the way. Finally, the word 'ahead' may indicate a sense of pushing onwards and persevering despite hardships. Participant C's collage includes the statement 'The hunger made me stronger'. This could relate to a tenacity and drive for a career (a career dream) that keeps a person strong when times are tough and when barriers to career dreams and goals need to be overcome.

Alluding to overcoming perceived career barriers, Participant B said, 'I am going to achieve my career by not just saying but also by acting and trying to do what I like'. In addition, Participant C stated:

'I've learnt that I have a future and I have to work for it. I also know that I should not back down now because if I do it will be a disappointment.' (Participant C)

Furthermore, it would appear that the participants' family members have encouraged them to overcome potential barriers to their career dreams. This was evident when Participant A stated:

'What stood out for me is like they [his parents] told me I should work hard and get degrees so that I can achieve my dream and don't be the same like them.' (Participant A)
The participants show a realistic understanding of what it is going to take to see their career aspirations become a reality and they are aware that 'there are no shortcuts to making money', as stated by Participant B.

From this discussion, it is evident that although all the participants perceive money to be the most prominent barrier to the fulfilment of their career dreams, they all display key characteristics of resilience (Ungar 2012, cited in Maree \& Di Fabio 2015). These include active agency, flexibility, the ability to take advantage of situations, and the ability to reflect on themselves, all of which are significant for seeing their career aspirations fulfilled.

\section{Concluding remarks}

This research explored the career aspirations of Grade 7 learners in a community school. The study highlighted the different factors that played a role in shaping the career aspirations of the three participants. Most of the responses indicated a positive disposition towards future career hopes and dreams. The findings are encouraging because the participants expressed a desire to reach their career goals and to make a difference in their future roles as citizens despite their current circumstances and experiences as adolescents. Although the study reveals only the 'tip of the iceberg' in terms of responding to the gap in research of this kind, its strength lies in its potential to guide further research and to inform contextually relevant career guidance interventions in primary schools. We therefore recommend that, apart from an isolated module as part of Life Orientation, structured and regular career interventions be introduced in primary schools, particularly for Grade 7 learners throughout their final year of primary school. We further recommend the design of a structured technical-vocational course, to be implemented as early as in Grade 7, that equips learners with the necessary skills for entrepreneurship.

It is hoped that this research will form part of the advancement of career education in South African primary schools and particularly in marginalised communities where the need for research into career development is so great. This is an approach to career counselling in which we personally believe and we consider that it would go a long way to benefitting the majority of learners in South Africa who, like the participants in this study, cannot afford the expensive services of professionals such as career counsellors and psychologists.

\section{Acknowledgements Competing interests}

The authors declare that they have no financial or personal relationships which may have inappropriately influenced them in writing this article.

\section{Authors' contributions}

The article is based on L.R.'s Master's dissertation that was supervised by B.D. Post examination L.R. wrote the first 
draft of the article and submitted to B.D., who then reworked the article and sent it to a critical reader. Critical comments by the reader were implemented by B.D. Both authors went through the article and B.D. sent it through for language editing, made recommended changes and submitted for review.

\section{References}

Arulmani, G., 2007, Pride and Prejudice: How do they matter to career development?, Centre for Guidance Studies, Derby.

Arulmani, G., 2011a, 'Enough for my mealie-meal: The cultural preparedness approach to the delivery of career services', in K. Maree (ed.), Career counselling, methods that work, pp. 24-33, Juta, Cape Town.

Arulmani, G., 2011b, 'Striking the right note: The cultural preparedness approach to developing resonant career guidance programmes', International Journal for Educational and Vocational Guidance 11(2), 79-93. https://doi.org/10.1007/ s10775-011-9199-y

Arulmani, G., Van Laar, D. \& Easton, S., 2001, 'Career planning orientation of disadvantaged high school boys: A study of socioeconomic and social cognitive variables', Journal of the Indian Academy of Applied Psychology 27(1-2), 7-17.

Ashby, J.S. \& Schoon, I., 2012, 'Living the dream? A qualitative retrospective study exploring the role of adolescent aspirations across the life span', Developmental Psychology 48(6), 1694-1706. https://doi.org/10.1037/a0027297

Auger, R.W., Blackhurst, A.E. \& Wahl, K.H., 2005, 'The development of elementaryaged children's career aspirations and expectations', Professional School Counseling 8(4), 322-329.

Babbie, E. \& Mouton, J., 2001, The social practice of social research, Oxford University Press, Cape Town.

Bandura, A., Barbaranelli, C., Caprara, G.V. \& Pastorelli, C., 2001, 'Self-efficacy beliefs as shapers of children's aspirations and career trajectories', Child Development 72(1), 187-206. https://doi.org/10.1111/1467-8624.00273

Bojabotseha, T.P., 2011, 'Dualism and the social formation of South Africa', African Journal of Hospitality, Tourism and Leisure 1(3), 1-8.

Bronfenbrenner, U., 2005, Making human beings human: Bioecological perspectives on human development, Sage, Thousand Oaks, CA.

Chartrand, J.M. \& Rose, M.L., 1996, 'Career interventions for at-risk populations: Incorporating social cognitive influences', The Career Development Quarterly 44(4), 341-353. https://doi.org/10.1002/j.2161-0045.1996.tb00450.x

Creed, P.A., Wong, O.Y. \& Hood, M., 2009, 'Career decision-making, career barriers and occupational aspirations in Chinese adolescents', International Journal for Educational and Vocational Guidance 9(3), 189-203. https://doi.org/10.1007/ s10775-009-9165-0

Creswell, J.W., 2012, Educational research: Planning, conducting, and evaluating quantitative and qualitative research, 4 th edn., Pearson, Boston, MA.

Department of Education, 2001, Education White Paper 6. Special needs education building an inclusive education and training system, Department of Education, Pretoria.

Department of Education, 2002, Revised National Curriculum Statement Grades R-9 (Schools). Life Orientation, Government Printers, Pretoria.

Department of Education, 2011, National Curriculum Statement (NCS). Curriculum and Assessment Policy Statement: Senior Phase. Grades 7-9, Department of Education, Pretoria

De Vos, A.S. \& Strydom, H., 2011, 'Intervention research', in A.S. De Vos, H. Strydom, C.B. Fouché \& C.S.L. Delport (eds.), Research at grass roots for the social sciences and human service professions, 4th edn., pp. 473-490, Van Schaik Publishers, Pretoria.

Diale, B.M., 2014, 'Black adolescents experiences of domestic violence in South Africa: A solution focused group therapy intervention approach', Mediterranean Journal of Social Sciences 5(16), 506-515. https://doi.org/10.5901/mjss.2014 v5n16p506

Donald, D., Lazarus, S. \& Lolwana, P., 2002, Educational psychology in social context, 2nd edn., Oxford University Press, Cape Town.

Fleisch, B., 2008, Primary education in crisis: Why South African schoolchildren underachieve in reading and mathematics, Juta and Company Ltd., Cape Town.

Flouri, E. \& Panourgia, C., 2012, Do primary school children's career aspirations matter? The relationship between family poverty, career aspirations and emotional and behavioural problems, CLS Working Paper, UK Centre for Longitudinal Studies, London.

Geldard, K. \& Geldard, D., 2012, Counselling adolescents. The proactive approach for young people, 3rd edn., Sage, London.

Gottfredson, L.S., 1981, 'Gottfredson's theory of circumscription, compromise, and self-creation', in S.D. Brown \& R.W. Lent (eds.), Career development and counseling: Putting theory and research to work, 3rd edn., pp. 1-100, Wiley, Hoboken, NJ.

Gottfredson, L.S., 1996, 'Gottfredson's theory of circumscription and compromise', in S.D. Brown \& L. Brooks (eds.), Career choice and development, 3rd edn., pp. 179-232, Jossey-Bass, San Francisco, CA

Hartung, P.J., Speight, J.D. \& Lewis, D.M., 1996, 'Individualism-collectivism and the vocational behavior of majority culture college students', The Career Development Quarterly 45(1), 87-96. https://doi.org/10.1002/j.2161-0045.1996.tb00464.x
Henning, E., Van Rensburg, W. \& Smit, B., 2004, Finding your way in qualitative research, Van Schaick, Pretoria.

Hook, D., 2009, 'Erikson's psychosocial stages of development', in J. Watts, K. Cockcroft \& N. Duncan (eds.), Developmental psychology, 2nd edn., pp. 283-311, UCT Press, Lansdowne.

Lapan, R.T., Adams, A., Turner, S. \& Hinkelman, J.M., 2000, 'Seventh graders' vocational interest and efficacy expectation patterns', Journal of Career Development 26(3) 215-229. https://doi.org/10.1177/089484530002600305

Lent, R.W., Brown, S.D. \& Hackett, G., 2000, 'Contextual supports and barriers to career choice: A social cognitive analysis', Journal of Counseling Psychology 47(1), 36-49. https://doi.org/10.1037/0022-0167.47.1.36

Maree, K. (ed.), 2011, Shaping the story: A guide to facilitating narrative career counselling, Sense Publishers, Rotterdam.

Maree, K. \& Di Fabio, A. (eds.), 2015, Exploring new horizons in career counselling: Turning challenge into opportunities, Sense Publishers, Rotterdam.

McGrath, S. \& Akoojee, S., 2007, 'Education and skills for development in South Africa: Reflections on the accelerated and shared growth initiative for South Africa' International Journal of Educational Development 27(4), 421-434. https://doi. org/10.1016/j.ijedudev.2006.07.009

Meece, J.L. \& Daniels, D.H., 2008, Child and adolescent development for educators, 3 rd edn., McGraw-Hill, New York.

Merriam, S.B., 2009, Qualitative research: A guide to design and implementation, Josey Bass, San Francisco, CA.

Nagengast, B. \& Marsh, H.W., 2012, 'Big fish in little ponds aspire more: Mediation and cross-cultural generalizability of school-average ability effects on self-concep and career aspirations in science', Journal of Educational Psychology 104(4), 1033-1053. https://doi.org/10.1037/a0027697

Nsamenang, A.B., 1992, Human development in cultural context: A third world perspective, Sage, Newbury Park, CA. https://doi.org/10.4135/97814833260301

Nsamenang, A.B., 2005, 'Human ontogenesis: An indigenous African view on development and intelligence', International Journal of Psychology 41(4), 293-297. https://doi.org/10.1080/00207590544000077

Nsamenang, A.B., 2009, 'Conceptualizing developmental assessment within Africa's cultural settings' in E.L. Grigorenko (ed.), Multicultural psychoeducational assessment, pp. 95-131, Springer, New York.

Patton, W. \& Creed, P., 2007, 'Occupational aspirations and expectations of Australian adolescents', Australian Journal of Career Development 16(1), 46-59. https://doi. org/10.1177/103841620701600108

Patton, W. \& Skorikov, V.B., 2007, 'Career development in childhood and adolescence: Introduction', in W. Patton \& B. Skorikov (eds.), Career development in childhood and adolescence, pp. 1-5, Sense Publishers, Rotterdam.

Quaglia, R.J. \& Cobb, C.D., 1996, 'Toward a theory of student aspirations', Journal of Research in Rural Education 12(3), 127-132.

Russel, S. \& Bakken, R.J., 2002, 'Development of autonomy in adolescence', in Family Life, Adolescence and Youth, University of Nebraska Lincoln, viewed 05 July 2016 , from http://www.ianrpubs.unl.edu/epublic/archive/g1449/build/g1449.pdf

Savickas, M.L., 2003, 'Advancing the career counseling profession: Objectives and strategies for the next decade', The Career Development Quarterly 52(1), 87-96. https://doi.org/10.1002/j.2161-0045.2003.tb00631.x

Schoon, I., 2001, 'Teenage job aspirations and career attainment in adulthood: A 17-year follow-up study of teenagers who aspired to become scientists, health professionals, or engineers', International Journal of Behavioral Development 25(2), 124-132. https://doi.org/10.1080/01650250042000186

Schoon, I. \& Parsons, S., 2002, 'Teenage aspirations for future careers and occupational outcomes', Journal of Vocational Behavior 60(2), 262-288. https://doi.org/ 10.1006/jvbe.2001.1867

Schoon, I. \& Polek, E., 2011, 'Teenage career aspirations and adult career attainment: The role of gender, social background and general cognitive ability', International Journal of Behavioral Development 35(3), 210-217. https://doi.org/10.1177/01 65025411398183

Schuette, C.T., Ponton, M.K. \& Charlton, M.L., 2012, 'Middle school children's career aspirations: Relationship to adult occupations and gender', The Career Development
Quarterly 60(1), 36-46. https://doi.org/10.1002/j.2161-0045.2012.00004.x

Shumba, A. \& Naong, M., 2012, 'Factors influencing students' career choice and aspirations in South Africa', Journal of Social Science 33(2), 169-178.

South African Schools Act No. 84, 1996, viewed 05 July 2016, from http://www. education.gov.za/

Statistics South Africa, 2015, Quarterly Labour Force Survey Quarter 3, viewed 05 July 2016, from http://www.statssa.gov.za/publications/P0211/P02114thQuarter2014. pdf

Stead, G.B., 1996, 'Career development of black South African adolescents: A developmental-contextual perspective', Journal of Counseling \& Development 74(3), 270-275. https://doi.org/10.1002/j.1556-6676.1996.tb01864.x

Swanson, J.L. \& Woitke, M.B., 1997, 'Theory into practice in career assessment for women: Assessment and interventions regarding perceived career barriers', Journal of Career Assessment 5(4), 443-462. https://doi.org/10.1177/106907279700500405

Taylor, S. \& Yu, D., 2009, The importance of socio-economic status in determining educational achievement in South Africa, unpublished working paper, Stellenbosch University, Stellenbosch.

Van der Berg, S., 2008, 'How effective are poor schools? Poverty and educational outcomes in South Africa', Studies in Educational Evaluation 34(3), 145-154. https://doi.org/10.1016/j.stueduc.2008.07.005

Venter, M., Watson, M. \& Fouche, P., 2006, A systematic review of career psychology research in South Africa, 1991-2004, unpublished manuscript. 
Visser, M. \& Moleko, A.G., 2012, Community psychology in South Africa, 2nd edn., Van Schaik, Pretoria.

Watson, M.B., 2010, 'Career psychology in South Africa: Addressing and redressing social justice', Australian Journal of Career Development 19(1), 24-35. https://doi. org/10.1177/103841621001900106

Watson, M.B., McMahon, M., Foxcroft, C. \& Els, C., 2010, 'Occupational aspirations of low socioeconomic black South African children', Journal of Career Development 37(4), 717-734. https://doi.org/10.1177/0894845309359351
Watson, M.B., McMahon, M. \& Longe, P., 2011, 'Occupational interests and aspirations of rural black South African children: Considerations for theory, research and practice', Journal of Psychology in Africa 21(3), 413-420.

Watson, M.B. \& Stead, G.B., 2002, 'Career psychology in South Africa: Mora perspectives on present and future directions', South African Journal of Psychology 32(1), 26-31.

Zunker, V.G., 1994, Career counselling. Applied concepts of life planning, 4th edn., Brooks/Cole, Pacific Grove. 